\title{
Effect of applying massage therapy on physical, physiological and behavioral states of premature neonates
}

\author{
Orban Ragab Bayomi ${ }^{1,2}$, Nahed Saied El-Nagger $* 1,2$ \\ ${ }^{1}$ Faculty of Nursing, Ain-Shams University, Cairo, Egypt \\ ${ }^{2}$ Faculty of Nursing, Umm Al-Qura University, Makkah, Saudi Arabia
}

Received: April 7, 2015

DOI: $10.5430 /$ jnep.v5n10p105
Accepted: July 12, 2015

Online Published: July 29, 2015

URL: http://dx.doi.org/10.5430/jnep.v5n10p105

\begin{abstract}
Background: Premature neonates are highly vulnerable group of the population. Premature births accounts for the highest mortality rate among infants in the first year of life. Massage therapy as non-invasive procedure that has positive effect on physical and developmental growth of premature neonates including; weight gain, promotion of neurologic development, decreased stress behavior, improved sleep, reduced rates of nosocomial infection and decreased mortality of hospitalized neonates. So, massage therapy is needed for the medical, emotional, psychological and physical wellbeing of premature neonates. The aim of the study was to evaluate the effect of applying massage therapy on physical, physiological and behavioral states of premature neonates. Methods: Design: It was a quasi-experimental. Subjects and Settings: A purposive sample containing sixty four premature neonates were chosen from the Neonatal Intensive Care Units (NICUs) in Maternity and Children Hospital, and Heraa General Hospital at Makkah Al-Mukaramah according to inclusion and exclusion criteria. Tools: Two tools were used as: Premature Neonates' Massage Observation Sheet and Neonatal Infant's Pain Scale (NIPS) (pre/post applying massage therapy).

Results: The mean scores of premature neonates' gestational age, birth weight, and weight at the onset of the study were 34.34 \pm 3.85 weeks, $2.09 \pm 0.17 \mathrm{~kg}$, and $2.56 \pm 0.73 \mathrm{~kg}$ respectively. Also, there were statistical significant differences between pre and post application of massage therapy $\left(\chi^{2}=23.32,26.31\right.$, and 32.17 at $P$ value $\left.\leq .05\right)$ regarding heart rate, temperature and occurrence of apnea respectively.

Conclusions: Applying massage therapy had a positive effect on premature neonates' physical, physiological and behavioral states, in addition to increasing their weight and decreasing their length of hospital stay. Recommendations: Emphasize the importance of applying massage therapy that is effective and safe non-invasive intervention in all NICUs as standard of care.
\end{abstract}

Key Words: Massage therapy, Premature neonates, Physical, Physiological, Behavioral states

\section{INTRODUCTION}

Prematurity is a term for the broad category of neonates born less than 37 weeks gestation. World Health Organization (WHO), defined preterm birth as all births born before completed 37 weeks of gestation since the first day of a women's last menstrual period, whereas preterm birth has long-term adverse consequences for health and is a major factor of neonatal mortality and morbidity. ${ }^{[1]}$

Although increased efforts to prevent prematurity, the prevalence of preterm birth in Saudi Arabia has increased.

*Correspondence: Nahed Saied El-Nagger; Email: nahidalngar@yahoo.com; Address: Faculty of Nursing, Ain-Shams University, Cairo, Egypt. 
Whereas, the number of preterm births at 32 to less than 37 weeks were 30,590 and this statistic may indicates the high admission rate to the Neonatal Intensive Care Units (NICUs) in Kingdom of Saudi Arabia hospitals every year regarding to $\mathrm{WHO}$ statistic, the rate of premature is $17 \%$ in the worldwide, $27 \%$ in industrialized and developing countries. $^{[1,2]}$

Worldwide, the preterm birth rate was estimated to be about $23 \%$ (range 5\% in parts of Europe to $18 \%$ in parts of Africa), and about 15 million neonates are born preterm each year. As these, preterm births $84 \%$ occurred at 32 to 36 weeks of gestational age (GA), $10 \%$ occurred at 28 to less than 32 weeks GA and 5\% occurred at less than 28 weeks GA. ${ }^{[3]}$

Premature neonates may be admitted to NICUs for their weight at birth is less than 2.500 grams. or any other health problems. However, NICU is a noisy environment with policy of minimal touch and it causes that premature neonates are deprived of sensory and tactile stimulation that is important for their growth. ${ }^{[4]}$ In turn, massage therapy with moderate pressure provided and passive movement of premature neonates' limbs increases their bone density and gain significantly more weight. ${ }^{[5]}$

Massage therapy as non-invasive procedure has positive effect on physical and developmental outcomes of premature neonates including weight gain that is associated with shorter hospital stays, promotion of neurologic and neuro-motor development, decreased stress behavior, improved infantparent attachment, improved sleep, reduced rates of nosocomial infection and mortality rate of hospitalized premature neonates. ${ }^{[6]}$

Furthermore, the current NICUs efforts for modifying the premature neonates' environment focuses on moderate pressure massage of physiologically stable premature neonates and firm/moderate pressure stroking. ${ }^{[7,8]}$

Consequently, massage has been proposed as a way of facilitating development and growth of neonates through its effects on increasing their blood flow, heart rate, digestion, and immunity. ${ }^{[9]}$ Massage might increase basal metabolism and nutrient absorption through endocrine effects such as increase in insulin and adrenaline, and decrease in cortisol, also has a significant impact on weight gain with shortening of hospital stay of up to 6 days. ${ }^{[10]}$ Additionally, massaging the premature neonates can help them to keep calm and this will assist them in adjusting their breathing, helping them to become less agitated or stressed, sleeping better, shut down from too much noise or light and be comforted more easily. ${ }^{[11]}$

Premature neonates are exposed daily to numerous stressors while being treated in the NICUs, resulting in heightened their stress behaviors and motor activity. Since, chronic exposure to stress has been associated with health and neurodevelopmental problems for the neonates. ${ }^{[12,13]}$ Also, previous study was examined the effects of massage therapy (two times massages/day for 5 days) on medically stable premature neonates being treated in the NICUs and confirmed that the premature neonates whom received the massage were showed reduced activity and stress behaviors, so massage therapy is associated with relaxation and decreased anxiety in both full term and preterm neonates. ${ }^{[9,13]}$

\subsection{Significance of the study}

In case of preterm births, the premature neonates are losses the calm uterus environment that is full of sensory stimulations required for their growth and development and are placed in the NICUs. This is a place full of light, noise and stress. Whereas, impairment in growth at early infancy, which is an important time for cellular hyperplasia and hypertrophy, can have permanent impacts on the future health of the neonates. The restriction caused in growth of premature neonates can stay with them till puberty. So, the researchers seek various methods to provide the premature neonates with complementary stimuli to help their growth and development in the NICUs. ${ }^{[14,15]}$

\subsection{Aim}

It was to evaluate the effect of applying massage therapy on physical, physiological and behavioral states of premature neonates.

\subsection{Research hypothesis}

Applying massage therapy has a positive effect on physical, physiological and behavioral states of premature neonates.

\section{SUBJECTS AND METHODS}

\subsection{Design}

A quasi-experimental study was utilized.

\subsection{Settings}

This study was carried out in Maternity and Children Hospital, and Heraa General Hospital at Makkah Al-Mukaramah, where these hospitals being of highest capacity of premature neonates.

\subsection{Subjects}

A purposive sample containing sixty four premature neonates was chosen according to inclusion and exclusion criteria:

\section{Inclusion criteria:}

- All Stable premature neonates as medically classified from both gender. 
- Gestational age was ranged between $32-\leq 36$ weeks.

- Premature neonates' weight at the onset of study was $\leq 2.500$ grams.

\section{Exclusion criteria:}

- High risk premature neonates with; infections, severe respiratory distress, congenital anomalies and premature neonates on supplemented oxygen therapy or mechanical ventilation.

\subsection{Tools of data collection}

Two tools were used for data collection as the following:

I. Premature neonates' massage observation sheet (Pre/Post applying massage therapy)

It was adapted from Akhavan $\mathrm{K}$ and Abd El-Fattah Z, ${ }^{[6,16]}$ it was used to assess physical, physiological and behavioral states of premature neonates. Some modifications were done by the researchers to be appropriate with the nature of the current study. It covered the following:

Premature neonates' characteristics as gender, birth weight, gestational age, weight and age at the onset of the study, as well as age at the end of the study and weight gain at discharge. These data were obtained from the neonate's hospital records.

Effect of applying massage therapy on premature neonates, it includes:

- Premature neonates' body temperature, heart rate, respiratory rate, occurrence of apnea and weight at discharge (physical and physiological states).

- Premature neonates' feeding patterns (type, amount and feeding tolerance in addition to their gastric motility).

- Premature neonates' duration of hospital stay after applying massage therapy.

- Premature neonates' crying and sleeping condition (behavioral state).

\section{Neonatal Infants Pain Scale (NIPS): (pre/post apply- ing massage therapy)}

It was adopted from Diego M et al. (2009) and Abdullah B et al. (2013). ${ }^{[10,13]}$ It is a pain assessment tool; it was used to assess sensitivity and quality of pain experienced by the premature neonates. NIPS consists of sixth items for pain assessment including; Facial expression, breathing patterns, arms and legs activities, cry, and state of arousal. Each item was scored from (0-1), whereas, score zero was determined when there was no reaction from the premature neonates and score one was determined when there was a reaction from the premature neonates. The total score for NIPS was sixth, and accordingly it classified according to the severity of pain into three levels:

- Score from 0-2 indicated no pain.

- Score from 3-4 indicated mild to moderate pain.

- Score from $\geq 4$ indicated severe pain.

\subsubsection{Preparatory phase Validity and reliability}

The researchers reviewed the past, current regional and international related literature covering all aspects of the study using textbooks, articles, journal and scientific magazines. This helped the researchers to be acquainted with the research problem and guided them in developing the study tools. To measure content validity of the study tools, the researchers assure that items of the tools were adequately represent what are supposed to measure by presented it to five experts for review and validation. Then the researchers performed two separate assessments at two different times; these two data sets from the same researchers and then compared with each other. Test retest method was used to determine the reliability of the tool, and the reliability score was 0.86 .

\subsubsection{Exploratory phase}

Pilot study It was carried out on seven premature neonates represent $10 \%$ of study sample to test the feasibility and applicability of the study tools, time required to fill it, its clarity and validity. The subjects included in the pilot study weren't involved in the study sample. The necessary modifications were done through adding or omission of unneeded or repeated items prior to data collection.

Field work The field work was performed from 1/10/2014 - 30/12/2014 to collect data by the researchers. The researchers were available all over the days per week (Saturday to Friday) in the morning shift by rotation in different study settings. The numbers of premature neonates taking/week were ranged from 5-6. The study tools were filled out by the researchers and the average times required for completion of each tool was around 15-20 minutes. The same researcher was applied the massage therapy every time for the same specified premature neonate.

\subsection{Procedures}

Preparing the Premature Neonates by the Researchers (Pre massage therapy):

- Assessing the premature neonates gestational age, diagnosis, birth weight, date of birth from the neonates' medical record.

- Selecting the premature neonates according to the inclusion and exclusion criteria.

- Assessing the premature neonates' vital signs (Temperature, Respiratory rate, Heart rate) occurrence of 
apnea, feeding patterns including type of feeding and amount, occurrence of vomiting in addition to gastric motility (bowel elimination), crying and their sleeping condition.

- Assessing the premature neonates' current weight.

- Assessing the premature neonates' level of pain during invasive procedures such as venipuncture for blood sampling or cannulation, and Oro-gastric tube insertion.

Applying massage therapy by the researchers:

(1) Performing the massage therapy approximately one hour after each feeding.

(2) Each massage session consisted of 5minutes of tactile stimulation, followed by 5 minutes of kinesthetic stimulation by stoking and concluded with another 5minutes period of tactile stimulation( each session consumed 15 minutes) through the following technique:

- Placing the neonate gently \& comfortably in prone position inside the incubator.

- Removing neonate's diaper.

- Rubbing the hands to warm it up.

- Starting the massage by gently talking \& speaking to the neonate in a calm tone.

- Placing the hands on the neonate's shoulders and gently stroke down to the toes to start the massage and repeating this step.

- Gently rubbing the neonate's stomach, flutter the hands over the stomach in a slow steady motion and repeating this step.

- Massaging the belly with the fingertips in a clockwise motion making small circular movements and pressing gently on the neonate's abdomen.

- Placing the hands on the middle of the neonate's chest and gently, move both hands outward and repeating this step.

- Moving the hands from shoulder to hip across the neonate's torso and repeating with the other side.

- Massaging the neonate's arms and hands.

- Holding the neonate's hand and wrist in one hand and form the letter $\mathrm{C}$ by the other hand.

- Gently, stroking the hand around the neonate's arm from the shoulder to the wrist.

- Massaging the neonate's palm and fingers by pressing the thumb into the palm by using circular movements and move around the hand.

- Squeezing the fingers lightly from pinky to thumb, pulling each and repeating with arm and hand massage on other arm.
- Moving the hands back and forth across the neonate's back in a zigzagging motion.

- Massaging from the neonate's neck to the bottom.

- Placing the hands on either side of the neonate's spine and massage downwards in small circular motions.

- Massaging the neonate's legs by using the same motion used in massaging the arms.

- Gently, roll the neonate over so that, the neonate was facing up.

After applying massage therapy (Post massage therapy):

- Assessing the premature neonates' vital signs (Temperature, Respiratory rate, Heart rate ) occurrence of apnea, feeding patterns including type of feeding and amount, occurrence of vomiting in addition to gastric motility (bowel elimination), wake and sleep states in addition to their crying.

- Assessing the neonates' level of pain during invasive procedures such as venipuncture for blood sampling or cannulation, and oro-gastric tube insertion.

- The massage therapy is continued for five consecutive days for all premature neonates.

- Each premature neonate had two sessions daily, and duration of each session was 15 minutes.

- The first session of massage therapy was performed one hour after the morning feeding (at $11 \mathrm{am}$ ) and the second session of massage therapy was performed one hour after the midday feeding (at $2 \mathrm{pm}$ ) by the researchers.

- Assessing the premature neonates' weight gain at discharge as documented in the nursing records by the NICUs nursing staff.

- Length of hospital stay for premature neonates after application of massage therapy is documented.

\subsection{Administrative design}

An official permission for data collection was obtained from the hospitals managers in the previously mentioned study settings through submission of official letters issued from Nursing College at Umm Al-Qura University.

\subsection{Statistical design}

The collected data were revised, organized, tabulated and analyzed by using the SPSS version (19). Numerical data was expressed as mean and $\pm \mathrm{SD}$, while qualitative data was expressed as frequency and percentage pre and post applying massage therapy. Chi-square $\left(\chi^{2}\right)$ was used to estimate the statistical significant differences pre and post applying massage therapy. Statistical significance was considered at $P$ $\leq .05$, highly statistically significant was considered at $P \leq$ 
.01 and no statistical significant differences was considered at $P \geq .05$.

\subsection{Ethical considerations}

- An official permission was obtained before data collection.

- An oral consent for agreement of mothers of premature neonates was obtained before applying massage therapy.

- Clear and simple clarification of the study nature and its expected outcomes were explained to NICUs managers and mothers of premature.

- Each sheet for neonates had code numbers to protect their confidentiality.

\subsection{Limitations of the study}

- Premature neonates whom were discharged before completion of five consecutive days, and applied two massage sessions/day were excluded from the study sample.
- Researchers were hoped to apply massage therapy through using an olive oil that might have effective neonatal outcomes but there wasn't agreed form the managers of the NICUs.

\section{RESULTS}

Table 1 showed that the mean scores of premature neonates' gestational age, birth weight, and weight at the onset of the study and age at the onset of the study were $34.34 \pm 3.85$ weeks, $2.09 \pm 0.17 \mathrm{~kg}, 2.56 \pm 0.73 \mathrm{~kg}$ and $7.45 \pm 3.94$ days respectively.

Figure 1 showed that $64 \%$ of the premature neonates were males and the rest $(36 \%)$ of them were females.

Regarding the premature neonates' diagnosis, Figure 2 demonstrates that all $(100 \%)$ of neonates were premature, whereas $56.30 \%$ and $25 \%$ of them had RDS and IDM respectively, in addition to the minority $(1.60 \%)$ of them were TTN.

Table 1. Distribution of premature neonates according to their characteristics

\begin{tabular}{|c|c|c|c|}
\hline Neonates' characteristics & Classifications & No. & $\%$ \\
\hline \multirow{4}{*}{ Gestational age (weeks) } & $30-<32$ & 8 & 12.5 \\
\hline & $32-<34$ & 24 & 37.5 \\
\hline & $34-\leq 36$ & 32 & 50.0 \\
\hline & Mean \pm SD & $34.34 \pm 3.85$ & \\
\hline \multirow{4}{*}{ Birth weight (kg) } & $<1.500$ & 22 & 34.3 \\
\hline & $1.500-<2.000$ & 26 & 40.7 \\
\hline & $2.000 \leq 2.500$ & 16 & 25.0 \\
\hline & Mean \pm SD & $2.09 \pm 0.17$ & \\
\hline \multirow{4}{*}{ Weight at the onset of the study $(\mathrm{kg})$} & $1.500-<2.000$ & 11 & 17.2 \\
\hline & $2.000-<2.500$ & 31 & 48.4 \\
\hline & $\geq 2.500$ & 22 & 34.4 \\
\hline & Mean \pm SD & $2.56 \pm .73$ & \\
\hline \multirow{4}{*}{ Age at the onset of the study (days) } & $<5$ & 18 & 28.2 \\
\hline & $5-<10$ & 30 & 46.8 \\
\hline & $\geq 10$ & 16 & 25.0 \\
\hline & Mean \pm SD & $7.45 \pm 3.94$ & \\
\hline
\end{tabular}

Concerning the premature neonates' physical and physiological states, Table 2 clarified that, there were statistical significant differences between pre and post application of massage therapy $\left(\chi^{2}=23.32,26.31\right.$ and 32.17 at $P$ value $\leq .05)$ regarding heart rate, temperature and occurrence of apnea respectively. Meanwhile, there was a high statistical significant difference regarding respiratory rate $\left(\chi^{2}=36.34\right.$ at $P$ value $\leq .00)$ pre and post application of massage therapy.
Regarding the premature neonates' behavioral state, Table 3 illustrated that, there were high statistical significant differences $\left(\chi^{2}=33.16,34.13\right.$ at $P$ value $\left.\leq .01\right)$ concerning crying and type of feeding respectively, meanwhile there was statistical significant difference $\left(\chi^{2}=25.67\right.$ at $P$ value $\left.\leq .05\right)$ regarding sleeping pre and post applying massage therapy.

As regards premature neonates' pain sensation, Figure 3 clarified that $10.90 \%, 37.50 \%$ and $51.60 \%$ of premature neonates 
had mild, moderate and severe pain pre applying massage therapy, compared to $62.50 \%, 35.90 \%$ and $1.60 \%$ of them post applying massage therapy respectively.

Table 4 showed that more than half $(57.9 \%)$ of premature neonates their weight gain at discharge was 150-200 gms. Whereas, the mean score of premature neonates weight gain were $187.18 \pm 60.80$ gms.

Table 5 illustrated that the mean score for premature neonates' length of hospital stay after applying massage therapy was $2.56 \pm 0.54$ days. Whereas, more than half $(57.8 \%)$ of them stayed 2-4 days after applying massage therapy.

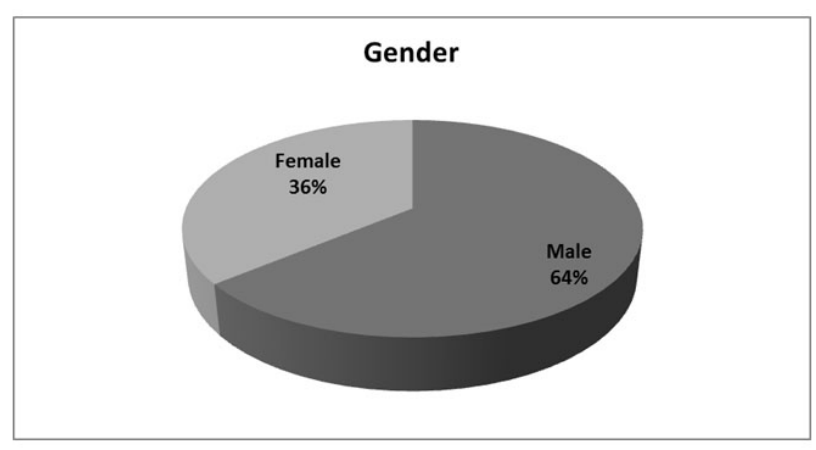

Figure 1. Distribution of premature neonates regarding their gender

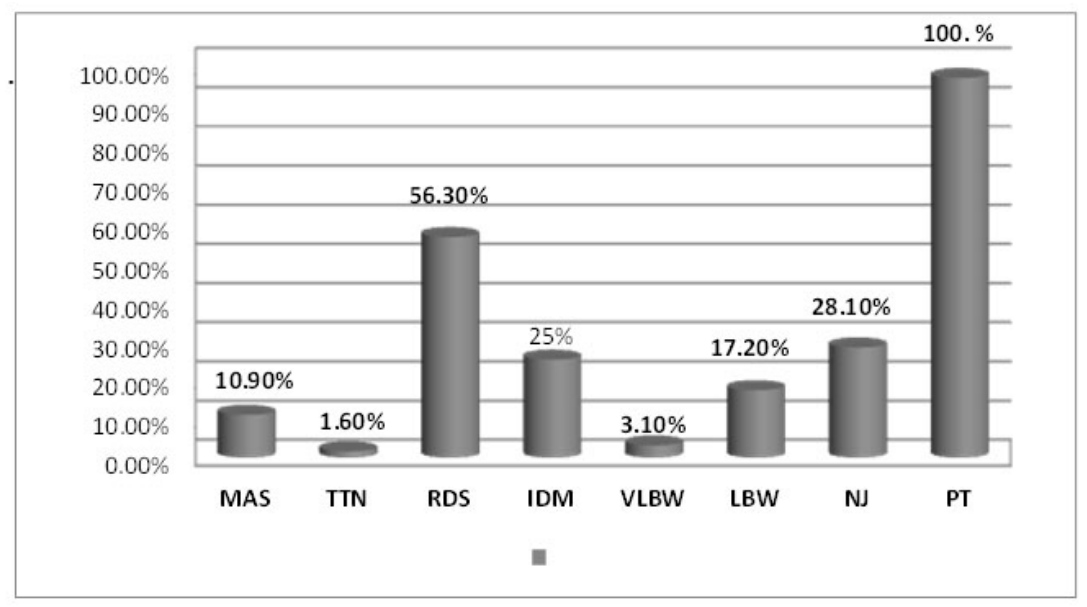

Figure 2. Distribution of premature neonates according to their diagnosis

Table 2. Distribution of premature neonates' physical and physiological states pre and post applying massage therapy

\begin{tabular}{|c|c|c|c|c|c|c|c|}
\hline \multirow{2}{*}{ Physical and Physiological states } & \multirow{2}{*}{ Classifications } & \multicolumn{2}{|l|}{ Pre } & \multicolumn{2}{|c|}{ Post } & \multirow{2}{*}{$\chi^{2}$} & \multirow{2}{*}{$P$-value } \\
\hline & & No. & $\%$ & No. & $\%$ & & \\
\hline \multicolumn{8}{|l|}{ 1.Heart Rate(b/min) } \\
\hline Bradycardia & $<120$ & 1 & 1.5 & 0 & 0.0 & 23.32 & $.02 * \mathrm{~S}$ \\
\hline Normal & $120-\leq 150$ & 39 & 61.0 & 64 & 100 & & \\
\hline Tachycardia & $>150$ & 24 & 37.5 & 0 & 0.0 & & \\
\hline \multicolumn{8}{|l|}{ 2. Resoiratory Rate } \\
\hline Bradypnea & $<35$ & 0 & 0 & 12 & 18.8 & 36.34 & $.00 * * \mathrm{HS}$ \\
\hline Normal & $35-\leq 50$ & 52 & 81.2 & 52 & 81.2 & & \\
\hline Tachypnea & $>50$ & 12 & 18.8 & 0 & 0.0 & & \\
\hline \multicolumn{8}{|l|}{ 3. Tempreture $\left({ }^{\circ} \mathrm{C}\right)$} \\
\hline Hypothermia & $<36.5$ & 46 & 71.7 & 10 & 15.6 & 26.31 & $.01 * \mathrm{~S}$ \\
\hline Normal & $36.5-\leq 37.2$ & 16 & 25.2 & 52 & 81.3 & & \\
\hline Hyperthermia & $>37.2$ & 2 & 3.1 & 2 & 3.1 & & \\
\hline \multicolumn{8}{|l|}{ 4. Apnea } \\
\hline Yes & & 20 & 31.3 & 4 & 6.3 & 32.17 & $.01 * \mathrm{~S}$ \\
\hline No & & 44 & 68.8 & 60 & 93.8 & & \\
\hline
\end{tabular}

$* P$ value $\leq .05$ Statistical significant differences $(S) ; * * P$ value $\leq .001$ High statistical significant differences (HS). 
Table 3. Distribution of premature neonates behavioral state pre and post applying massage therapy

\begin{tabular}{|c|c|c|c|c|c|c|c|}
\hline \multirow{2}{*}{ Behavioral state } & \multirow{2}{*}{ Classifications } & \multicolumn{2}{|l|}{ Pre } & \multicolumn{2}{|l|}{ Post } & \multirow{2}{*}{$\chi^{2}$} & \multirow{2}{*}{$P$-value } \\
\hline & & No. & $\%$ & No. & $\%$ & & \\
\hline \multirow{2}{*}{ 1. Crying } & Yes & 59 & 92.2 & 7 & 10.9 & 33.16 & $.006^{* *} \mathrm{HS}$ \\
\hline & No & 5 & 7.8 & 57 & 89.1 & & \\
\hline \multirow{2}{*}{ 2. Sleeping } & Yes & 11 & 17.2 & 55 & 85.9 & 25.67 & $.42 * \mathrm{~S}$ \\
\hline & No & 53 & 82.8 & 9 & 14.1 & & \\
\hline \multirow{3}{*}{$\begin{array}{l}\text { 3. Feeding Patterns } \\
\text { Type of Feeding }\end{array}$} & NGT & 15 & 23.4 & 13 & 20.3 & 34.13 & \\
\hline & Bottle & 43 & 67.1 & 27 & 42.2 & & $.00 * *$ HS \\
\hline & Breast & 6 & 9.5 & 24 & 37.5 & & \\
\hline \multirow{2}{*}{ Amount of Feeding } & Increased & 23 & 35.9 & 60 & 93.8 & 35.6 & $.00 * *$ HS \\
\hline & Decreased & 41 & 64.1 & 4 & 6.2 & & \\
\hline \multirow{2}{*}{ Occurrence of vomiting } & Yes & 57 & 89.1 & 9 & 14.1 & 31.06 & $.005^{* *} \mathrm{HS}$ \\
\hline & No & 7 & 10.9 & 55 & 85.9 & & \\
\hline \multirow{3}{*}{$\begin{array}{l}\text { Bowel elimination } \\
\text { (Frequency) }\end{array}$} & $<2$ Times & 41 & 64.1 & 2 & 3.12 & 30.1 & \\
\hline & 2-4 Times & 13 & 20.3 & 55 & 85.9 & & $.00^{* *}$ HS \\
\hline & > 4 Times & 10 & 15.6 & 7 & 10.9 & & \\
\hline
\end{tabular}

${ }^{*} P$ Value $\leq .05$ Statistical significant differences $(\mathrm{S}) ;{ }^{*} P$ value $\leq .01$ high Statistical significant differences (HS).

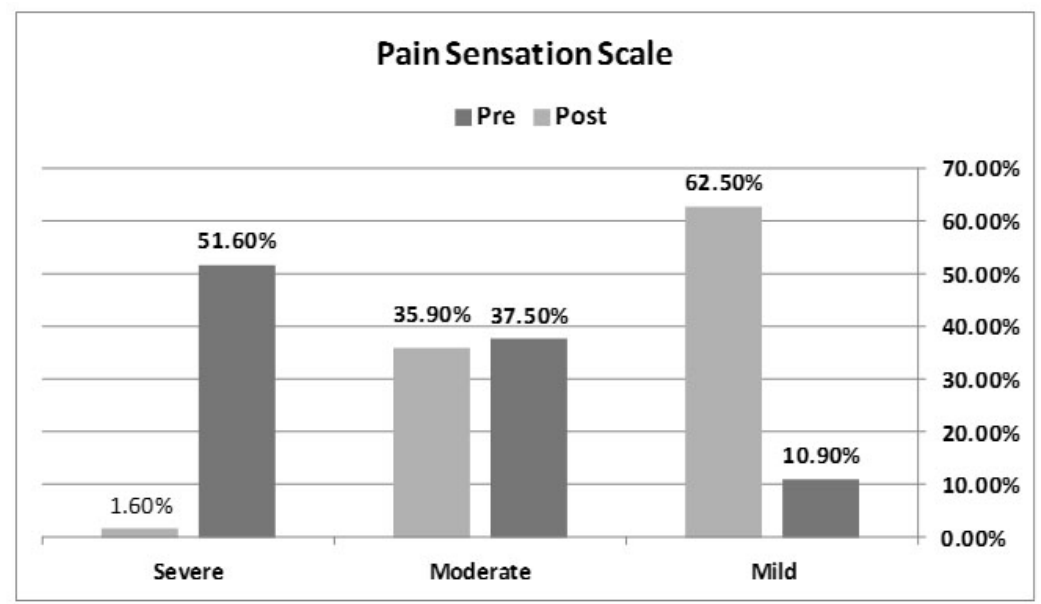

Figure 3. Distribution of premature neonates according to their pain sensation pre and post applying massage therapy

Table 4. Mean score of premature neonates weight gain at discharge after applying massage therapy

\begin{tabular}{lll}
\hline Weight (gms) & No. & \% \\
\hline$<150$ & 20 & 31.2 \\
$150-<200$ & 37 & 57.9 \\
$200 \leq 250$ & 7 & 10.9 \\
Mean \pm SD & $\mathbf{1 8 7 . 1 8} \pm \mathbf{6 0 . 8 0}$ & \\
\hline
\end{tabular}

Table 5. Distribution of premature neonates according to their length of hospital stay after applying massage therapy

\begin{tabular}{llll}
\hline Length of hospital stay (days) & No. & $\mathbf{\%}$ & Mean \pm SD \\
\hline$<2$ & 17 & 26.6 & \\
$2-4$ & 37 & 57.8 & \\
$>4$ & 10 & 15.6 & $\mathbf{2 . 6 5} \pm \mathbf{0 . 5 4}$ \\
Total & $\mathbf{6 4}$ & $\mathbf{1 0 0}$ & \\
\hline
\end{tabular}

Published by Sciedu Press

\section{Discussion}

Premature neonates are vulnerable group of the population. Premature births accounts the highest mortality rate among infants in the first year of life. ${ }^{[3,14]}$ Premature neonates are admitted in NICUs for their prematurity or health problems. NICU is noisy environment with policy of minimal handling to avoid acquired infection and it causes that premature neonates are deprived from sensory and tactile stimulation that is important in their growth. ${ }^{[15]}$

Massage is defined as a systematic touch by human hands, which stimulates the tactile sense of the neonates and which has been documented to has a positive effect for both preterm and full term neonates. Massage therapy technique as a noninvasive procedure has positive effect on physical and developmental growth of premature neonates including weight gain improved sleep, reduced rates of nosocomial infec- 
tion and decreased mortality of infants during hospitalization. ${ }^{[17,18]}$ Therefore, this study was aimed to evaluate the effect of applying massage therapy on physical, physiological and behavioral states of premature neonates.

On investigating the premature neonates' characteristics, the present study showed that half of premature neonates were $34 \leq 36$ weeks of gestational age. Meanwhile, regarding their birth weight nearly less than half of premature neonates' their birth weight is $1.500-2.000 \mathrm{~kg}$. These results were supported by Bridget C (2012) and Badr B et al. $(2011)^{[19,20]}$ whom emphasized that the birth weight is an indicator for health condition of the neonates. Shah $\mathrm{S}$, et al. (2011) ${ }^{[21]}$ mentioned that the neonate's gestational age and birth weight indicates the adequacy of growth intrauterine, whereas the organ systems maturity depends on gestational age.

Concerning the premature neonates' diagnosis, results of the current study reported that all neonates were preterm (PT), whereas more than half of them and nearly one quarter of them were accompanied with mild and moderate respiratory distress syndrome (RDS) and low birth weight and very low birth weight (LBW \&VLBW) respectively, in addition to minority of them were diagnosed as transient tachypnea of newborn (TTN). These results were supported by George T (2014) and Richard M (2014), ${ }^{[22,23]}$ whom reported that $50.5 \%$ of premature births were associated with higher rates of LBW compared to full term births, and the risk increased several times with premature birth. So, massage therapy has not any harm effects and it can increase weight of neonates with more weeks of gestation above thirty weeks and medically stable. ${ }^{[5]}$

Regarding the effect of applying massage therapy on premature neonates' physical and physiological states pre and post, results of the current study demonstrated that, there were statistical significant differences $\left(\chi^{2}=23.32,26.31\right.$ and 32.17 at $P$ value $\leq .05)$ concerning heart rate, temperature and occurrence of apnea respectively. Meanwhile, there was a high statistical significant difference regarding respiratory rate $\left(\chi^{2}=36.34\right.$ at $P$-value $\left.\leq .001\right)$ pre and post applying of massage therapy. These results were in agreement with De Almeida M et al. (2014), ${ }^{[24]}$ whom documented that massage therapy for premature neonates' maintained their body temperature and had a positive effect on their heart rate. In this context, massaged premature neonates slept less, had decrease in heart rate, as well increase in vagal tone and less bradycardia and apnea. ${ }^{[25]}$

On investigating behavioral state of premature neonates pre and post applying massage therapy, findings of the current study founded that, there were high statistical significant differences $\left(\chi^{2}=33.16,34.13\right.$ at $P$ value $\left.\leq .01\right)$ concerning crying and type of feeding respectively pre and post applying massage therapy, meanwhile there was statistical significant difference $\left(\chi^{2}=25.67\right.$ at $P$ value $\left.\leq .05\right)$ regarding sleeping pre and post applying massage therapy.

As this regards, Badiee $\mathrm{Z}$ et al. (2012) and Field $\mathrm{T}$ et al. $(2010)^{[4,12]}$ confirmed that, premature neonates studies have documented increased weight gain, reduced stress and crying, decreased pain responses, enhanced maturation of electroencephalographic activity and visual function, improved neurologic, behavioral and motor development, a decrease pattern of fussiness and modified sleep patterns. Additionally, tactile stimulation conducive to neural excitation was reported to result in better additive responses, more variations in hand movement and less hypo tony. ${ }^{[26]}$

According to Manju C and Shilpi S (2014), ${ }^{[26]}$ whom pointed out that moderate pressure massage with tactile stimulation, can improve weight gain of LBW neonates by increasing vagal activity, more sucking increased insulin release, reduced energy expenditure, decrease norepinephrine serum level, increased gastric motility and better absorption of nutrients. These could be explained that tactile stimulation improved premature neonates' circulation and increased blood supply to the stomach that accelerates gastric motility and digestion.

As regards premature neonates' pain sensation according to Neonatal Infant Pain Scale (NIPS), results of the present study clarified that, less than one quarter of premature neonates' had mild pain sensation compared with approximately two thirds of them pre and post applying massage therapy respectively, conversely slightly more than half of premature neonates compared with the minority of them experienced severe pain pre and post applying massage therapy respectively. These results were consistent with Ang J et al. (2012) ${ }^{[9]}$ whom founded that massage therapy for premature neonates reduced stress of them as reported by decreased pain responses and serum cortisol levels; improved motor, behavioral and their neurological development.

Regarding the premature neonates' length of hospital stay after applying massage therapy, finding of the current study showed that, more than half of premature neonates their length of hospital stay was ranged between 2-4 days after applying massage therapy. This result was consistent with Ang J et al. (2012) and Mutlu Y et al. (2011) ${ }^{[9,27]}$ whom revealed that, massage therapy enhanced immune system and less sepsis that leading to decrease length of hospital stay.

As this regards Kimberly E et al. (2013) and Rangey PS and Megha S (2014) ${ }^{[28,29]}$ emphasized that premature neonates with initial poor motor performance had significantly more improvement in motor and neurologic outcomes and decrease 
length of stay after applying massage when compared to those not receiving massage, also massage therapy was associated with shorter hospital stays in very low birth.

On studying the premature neonates' weight at discharge, more than half of them gained from 150-200 gms after applying massage therapy, this result was in agreement with Golchin M et al. (2010) and Tekgündüz K et al. $(2014)^{[8,30]}$ who mentioned that weight gain is the most consistent indicator which is associated with massage therapy in neonates. Also, stable 28-34 weeks neonates whom were massaged for five days, three times/day by a well-trained nurse, had significantly increase their weight than those weren't massaged. Body massage increased mean of weight of LBW neonates and it can be used as a simple effective and safe non-invasive procedure. ${ }^{[12,31]}$

In this context, therapeutic touch in premature neonates by different modalities was reported to have several positive outcomes. Moderate massage resulted in more weight gain. A number of studies have been discovered the advantages of providing touch and the results in most cases are promising. ${ }^{[26,31]}$

\section{Conclusion}

The current study concluded that applying massage therapy had a positive effect on premature neonates' physical, physiological and behavioral states, in addition to increasing their weight, and decreasing their length of hospital stay.

\section{Recommendations}

(1) Emphasize the importance of applying massage therapy that is effective and safe non-invasive intervention in all NICUs as standard of care.

(2) Training program should be provided for all nurses working in NICUs as regards applying massage therapy and its benefits for premature neonates and their mothers.

(3) Encourage mothers to apply massage therapy pre discharge through teaching sessions and using booklet, massage therapy guidelines to improve mothers - infant bonding.

(4) Further study should be conducted in all NICUs to assess the neonatal nurse's knowledge, attitudes and performance regarding massage therapy and its effect on health status of premature neonates.

\section{ACKNOWLEDgeMENTS}

The researchers thank the mothers for their agreement for applying this study on their premature neonates. They would also like to thank NICUs nursing staff members and all those who supported this study.

\section{CONFLicts OF INTEREST Disclosure}

The authors declare that there is no conflict of interest statement.

\section{REFERENCES}

[1] World Health Organization (WHO). March of Dimes, Partnership for Maternal, Newborn \& Child Health, Save the Children. Born too soon: the global action report on preterm birth. 2012.

[2] Isfahan J. Weight gain in premature infants Med School. 2013; 29 : 804-805.

[3] Markestad T, Kaaresen P, Rønnestad A. Early death, morbidity, and need of treatment among extremely premature infants. Pediatrics. 2008; 115: 1289. PMid:15867037 http://dx.doi.org/10.1542 /peds. 2004-1482

[4] Badiee Z, Samsamshariat S, Pourmorshed P. Effect of Massage on Weight Gain in Premature Infants. Iranian Journal of Neonatology. 2012.

[5] Akhavan K, Arbasil G, Fallah R, et al. Effect of body massage on increase of low birth weight neonate's growth parameters: A randomized clinical trial. Iran J Reprod Med. 2013; 11(7): 583-588.

[6] Akhavan K. Effect of body massage on increase of low birth weight neonates' growth parameters. Iran J Reprod Med. 2013; 11(7): 583$588,779$.

[7] Kulkarni A, Kaushik S, Gupta P, et al. Massage and touch therapy in neonates: the current evidence. Indian Pediatric magazine. 2010; 47: 771-776. http://dx.doi.org/10.1007/s13312-010-0114-2

Published by Sciedu Press
[8] Golchin M, Rafati P, Taheri P, et al. Effect of deep massage on increasing body weight in low birth weight infants. 2010; 46-50.

[9] Ang Y, Lua L, Mathur A, et al. Randomized placebo-controlled trial of massage therapy on the immune system of preterm infants. Pediatrics. 2010; 130(6): e1549-e1558.

[10] Diego MA, Field T, Hernandez-Reif M. Procedural pain heart rate responses in massaged preterm infants. Infant Behavior \& Development. 2009; 32 (2): 226-229. PMid:19185352 http://dx.doi.o $\mathrm{rg} / 10.1016 / \mathrm{j}$. infbeh.2008.12.001

[11] Loving Touch $®$ \& CIMI $\circledast$. Baby massage can help keep your baby calm and content. 2014.

[12] Field T, Diego M, Hernandez-Reif M. Preterm infant massage therapy research: a review. Infant Behavioral Development. 2010; 33: 115-124. PMid:20137814 http://dx.doi.org/10.1016/j.inf beh.2009.12.004

[13] Abdallah B, Kurdahi L, Hawwari M. The efficacy of massage on short and long term outcomes in preterm infants. Infant Behavior \& Development. 2013; 36: 662. PMid:23932956 http: //dx.doi.org/10.1016/j.infbeh.2013.06.009

[14] Islami Z, Fallah R, Mosavian T, et al. Growth parameters of NICU admitted low birth weight preterm neonates at corrected ages of 6 and 12 month. Iran J Reprod Med. 2012; 10: 459-464. PMid:25246912 
[15] Waldemar C, Kliegman M, Stanton B, et al. The high-risk infant. Nelson Textbook of Pediatrics.19th Ed. Philadelphia, Saunders: 2011 698-711.

[16] Abd El-Fattah Z. Neonatal Morbidity and Mortality in Upper Egypt (Sohag). A follow-up study, Doctorate Thesis, Nursing practices, High Institute of Nursing, Cairo University. 2010; 30: 110-115.

[17] Kulkarni A, Kaushik S, Gupta P, et al. Massage and touch therapy in neonates: the current evidence. Indian Pediatric J. 2010; 47: 771-776. http://dx.doi.org/10.1007/s13312-010-0114-2

[18] Sandra $P$. The use of massage for neonates requiring special care. Complementary Therapies in Nursing \& Midwifery. 2013; 94.

[19] Bridget C. Causes of premature Birth. Perinatology. 2012; 24: 23.

[20] Badr B, Abdallah B, Purdy B. Nursing care in Lebanon: A nursing perspective. Newborn and Infant Nursing Reviews. 2011; 111(2): 94 http://dx.doi.org/10.1053/j.nainr.2011.04.006

[21] Shah P, Balkhair T, Ohlsson A, et al. Intention to become pregnant and low birth weight and preterm birth: a systematic review. Maternal and Child Health Journal. 2011; 15(2): 205-16. PMid:20012348 http://dx.doi.org/10.1007/s10995-009-0546-2

[22] George M. Short-term complications of the premature infant Literature review current through. 2014. Available from: http://www. uptodate.com/contents/short-term-compl ications-of-the-premature-infant

[23] Richard M. Pathogenesis, clinical presentation, and diagnosis of apnea of prematurity. J Pediatr. 2014; 288-295.
[24] De Almeida M, Guinsburg R, Sancho G. Hypothermia and early neonatal mortality in preterm infants. J Pediatr. 2014; 164: 271. PMid:24210925 http://dx.doi .org/10.1016/j.jpeds. 2013. 09.049

[25] Miller M, Martin M, Polin R, et al. Pathophysiology of apnea of prematurity. eds. Fetal and Neonatal Physiology. 4th.ed. Philadelphia, PA: Saunders Elsevier; 2011; chap 91.

[26] Manju C, Shilpi S. Therapeutic Touch Modalities and Premature Neonate's Health Outcome. J Neonatal Biol. 2014; 3: 4.

[27] Mutlu Y, Saygin G, Yilmaz G, et al. Neonatal Sepsis Caused by Gram-negative Bacteria in a Neonatal Intensive Care Unit: A Six Years Analysis. 2011.

[28] Kimberly E, Mary A, Highton C, et al. Nurses' Perspectives on Neonatal Massage Therapy in the Neonatal Intensive Care Unit. 2013.

[29] Rangey PS, Megha S. Comparative Effect of Massage Therapy versus Kangaroo Mother Care on Body Weight and Length of Hospital Stay in Low Birth Weight Preterm Infants. International Journal of Pediatrics. 2014. PMid:24976830 http://dx.doi.org/10.1155 /2014/434060

[30] Tekgündüz K, Gürol A, Apay S, et al. Effect of abdomen massage for prevention of feeding intolerance in preterm infants. Italian Journal of Pediatrics. 2014, 40: 89. PMid:25394549 http: //dx.doi.org/10.1186/s13052-014-0089-z

[31] Aly F, Murtaza G. Massage Therapy in Preterm Infants. Pediatrics \& Therapeutics. 2013. 